\title{
Flow-Injection Spectrophotometric Determination of Novalgin in Pharmaceuticals Using Micellar Medium
}

\author{
Patrícia Los Weinert,* João Roberto Fernandes,** Leonardo Pezza,* and \\ Helena Redigolo Pezza* ${ }^{* \dagger}$ \\ *Instituto de Química-UNESP, P. O. Box 355, CEP 14801-970, Araraquara, SP, Brazil \\ **Departamento de Química-FC/UNESP, 17033-360, Bauru, SP, Brazil
}

\begin{abstract}
A sensitive flow-injection (FI) procedure with spectrophotometric detection in a micellar medium is proposed for the determination of novalgin. The method is based on the instantaneous formation of a red-orange product $\left(\lambda_{\max }=510 \mathrm{~nm}\right)$ after the reaction between novalgin and $p$-dimethylaminocinnamaldehyde ( $p$-DAC) in a dilute acid medium. The sensitivity of this reaction was increased by a factor of 5.6 in the presence of sodium dodecyl sulfate (SDS). Experimental design methodologies were used to optimize the chemical and FI variables. The calibration curve was linear in the range of $1.45 \times 10^{-6}$ to $2.90 \times 10^{-5} \mathrm{~mol} \mathrm{~L}^{-1}$ with an excellent correlation coefficient $(r=0.9999)$. The detection limit was $1.31 \times 10^{-7} \mathrm{~mol} \mathrm{~L}^{-1}(n=20$, RSD $=2.0 \%)$. No interferences were observed from the common excipients. The results obtained by the proposed method were favorably compared with those given by the iodometric reference method at $95 \%$ confidence level.
\end{abstract}

(Received April 23, 2007; Accepted July 17, 2007; Published December 10, 2007)

\section{Introduction}

Novalgin (sodium salt of 1-phenyl-2,3-dimethyl-4-methylaminomethane sulfonate-5-pyrazolone; analgin, dipyrone, metamizol) is a pyrazolone derivate widely used as an analgesic, antipyretic and antispasmodic in several pharmaceutical formulations. ${ }^{1}$ It was introduced into clinical practice in 1922. Due to its strong analgesic effect, available parenteral formulation and low cost, novalgin is extensively used in many countries. ${ }^{2,3}$

Various methods have been established for the quantitative determination of novalgin in pharmaceutical formulations including titrimetry in aqueous $s^{4,5}$ and non-aqueous ${ }^{6}$ media, HPLC with UV detection, ${ }^{7-9}$ voltammetry, ${ }^{10}$ polarography ${ }^{11}$ and spectrophotometry. ${ }^{12-18}$

Nowadays, more strict regulation related to the quality control of pharmaceuticals has led to increasing demands for the automation of the analytical assays carried out in appropriate control laboratories. Flow injection analysis (FIA) is a versatile instrumental tool due to its simplicity, small sample volumes, low reagent consumption, and high reproducibility; such analysis generally allows the acquisition of a great number of analytical data at low cost and in a relatively short analysis time. ${ }^{19}$ Flow injection procedures employing various types of detection has also been applied for novalgin analysis in pharmaceuticals, such as: amperometric, ${ }^{20}$ turbidimetric, ${ }^{21}$ potentiometric, ${ }^{22}$ chemilumimetric, ${ }^{23}$ fluorometric ${ }^{24}$ and spectrophotometric ${ }^{25,26}$ detection. To the best of our knowledge, there are no reports on flow-injection spectrophotometric determination of novalgin in micellar media.

The analytical utility of micelles is evident in a wide variety

$\dagger$ To whom correspondence should be addressed.

E-mail: hrpezza@iq.unesp.br of analytical techniques from instrumental to classical wet chemical methods of analysis. Micelles can increase the molar absorptivity of the chromophore, modify equilibrium constants and reaction yields, shift spectral bands, co-solubilize samples, reagents and products, and catalyze reactions. ${ }^{27}$

The micellar medium can improve the spectrophotometric detection in flow injection analysis by providing an increase in the formation rate of the chromophore and an increase in the sensitivity. ${ }^{27}$ In addition, the surfactants can also be useful in softening the experimental conditions required to carry out the reaction, such as: reducing the temperature or acid and reagent concentrations. ${ }^{27,28}$ This is of interest for simplification of manual and automated analytical procedures, and will contribute to green chemistry, ${ }^{29}$ due to its capability of decreasing the reagent consumption and as a consequence, minimizing effluent generation.

The present work describes an FI spectrophotometric procedure for the determination of novalgin using sodium dodecyl sulfate (SDS) micellar medium to greatly improve the sensitivity of the condensation of $p$-dimethylaminocinnamaldehyde ( $p$-DAC) with novalgin, in acid medium. Experimental design approaches and the response surface analysis methodology were used as methods of maximizing the response.

The development and validation of the proposed FI spectrophotometric procedure in micellar medium and its application to novalgin determination in pharmaceuticals are described. The proposed procedure is highly sensitive, simple, and rapid, does not involve heating steps and has very small sample consumption when compared with other procedures.

\section{Experimental}

\section{Apparatus}

The flow-through measurements were carried out using an 


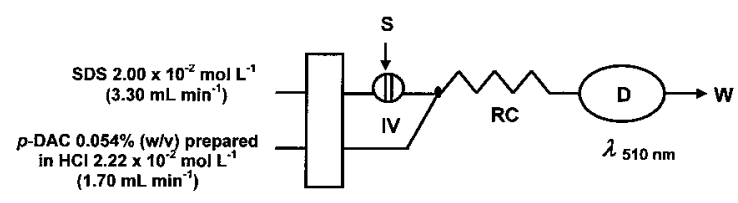

Fig. 1 Schematic diagram of the proposed flow-injection procedure. PP, peristaltic pump; IV, injection valve; S, sample loop volume $(880 \mu \mathrm{L})$; RC, reaction coil $(250 \mathrm{~cm})$; $\mathrm{D}$, detector; $\mathrm{W}$, waste.

ASIA system from Ismatec (Zürich, Switzerland) equipped with a four-channel pump (IS 7610) with variable speed (1 - $50 \mathrm{rpm}$ ) for propelling the fluids and a sample injection valve (IS 7630, Rheodyne 5041, USA). An HP 8453A (Hewlett Packard, USA) diode array UV/Vis spectrophotometer equipped with a flowcell of $10 \mathrm{~mm}$ path length and $80 \mu \mathrm{L}$ inner volume from Hewlett Packard (Hewlett Packard, USA) was used for the continuously monitoring of the absorbance at $510 \mathrm{~nm}$. The FIA peak is registered as the time-dependence of the absorbance at this wavelength.

The FI diagram is represented in Fig. 1. The samples and the reagent ( $p$-DAC $0.054 \%(\mathrm{~m} / \mathrm{v})$ prepared in $\mathrm{HCl} 2.22 \times 10^{-2} \mathrm{~mol}$ $\mathrm{L}^{-1}$ ) solutions were pumped through Tygon ${ }^{\circledR}$ pumping tubes of $1.42 \mathrm{~mm}$ i.d., and the SDS $2.00 \times 10^{-2} \mathrm{~mol} \mathrm{~L}^{-1}$ solution was pumped through Tygon ${ }^{\circledR}$ pumping tube of $2.06 \mathrm{~mm}$ i.d. The standard connectors, sample loop and reaction coils were made of polytetrafluoroethylene tubes (PTFE) of $0.8 \mathrm{~mm}$ i.d. Endfittings and connectors (Omnifit, New York, USA) were used.

\section{Reagents and solutions}

For the preparation of the solutions and samples, deionized water (Milli-Q Gradient system) and grade A glassware were used throughout. Analytical-reagent or pharmaceutical grade chemicals were used. The excipients used in the interference study were of pharmaceutical grade.

$\mathrm{HCl}$ stock solution 0.479 mol L-1 was prepared by convenient dilution of concentrated acid (Mallinckrodt, Xalostoc, Mexico) with deionized water and standardized by volumetric procedure. Working solutions were prepared by appropriate dilution of the stock solution with deionized water.

A standard novalgin solution $\left(2.90 \times 10^{-4} \mathrm{~mol} \mathrm{~L}^{-1}\right)$ was prepared by dissolving $10.0 \mathrm{mg}$ of novalgin (Daiichi Seiyaku Co. Ltd., Tokyo, Japan, 99.9\%) in $100 \mathrm{~mL}$ of deionized water and was standardized as described in the literature. ${ }^{5}$ Working standard solutions $\left(1.45 \times 10^{-6}\right.$ to $\left.2.90 \times 10^{-5} \mathrm{~mol} \mathrm{~L}^{-1}\right)$ were obtained by measuring the appropriate volume of the novalgin stock solution. After that, $5 \mathrm{~mL}$ of SDS $0.10 \mathrm{~mol} \mathrm{~L}^{-1}$ was added and the volume was completed with water to $25 \mathrm{~mL}$ in a volumetric flask.

$p$-Dimethylaminocinnamaldehyde ( $p$-DAC) (Aldrich, Milwaukee, USA) $0.054 \%(\mathrm{~m} / \mathrm{v})$ was prepared in $\mathrm{HCl} 2.22 \times$ $10^{-2} \mathrm{~mol} \mathrm{~L}^{-1}$ (Mallinckrodt, Xalostoc, Mexico) and it was kept refrigerated no more than 1 week.

Sodium dodecyl sulfate (SDS) (Sigma, St. Louis, USA) aqueous solutions $\left(1.00 \times 10^{-1} \mathrm{~mol} \mathrm{~L}^{-1}\right)$ were prepared weekly. Working solutions were prepared by appropriate dilution of the stock solution with deionized water.

\section{Recommended procedure}

For the flow injection procedure, the following optimum conditions are suggested (Fig. 1): a sample volume (S) of 880 $\mu \mathrm{L}$ is injected via an injection valve (IS 7630, Rheodyne 5041, USA) into the carrier stream of the SDS solution $\left(2.00 \times 10^{-2}\right.$ mol L-1) pumped by a peristaltic pump (PP) at $3.30 \mathrm{~mL} \mathrm{~min}^{-1}$.
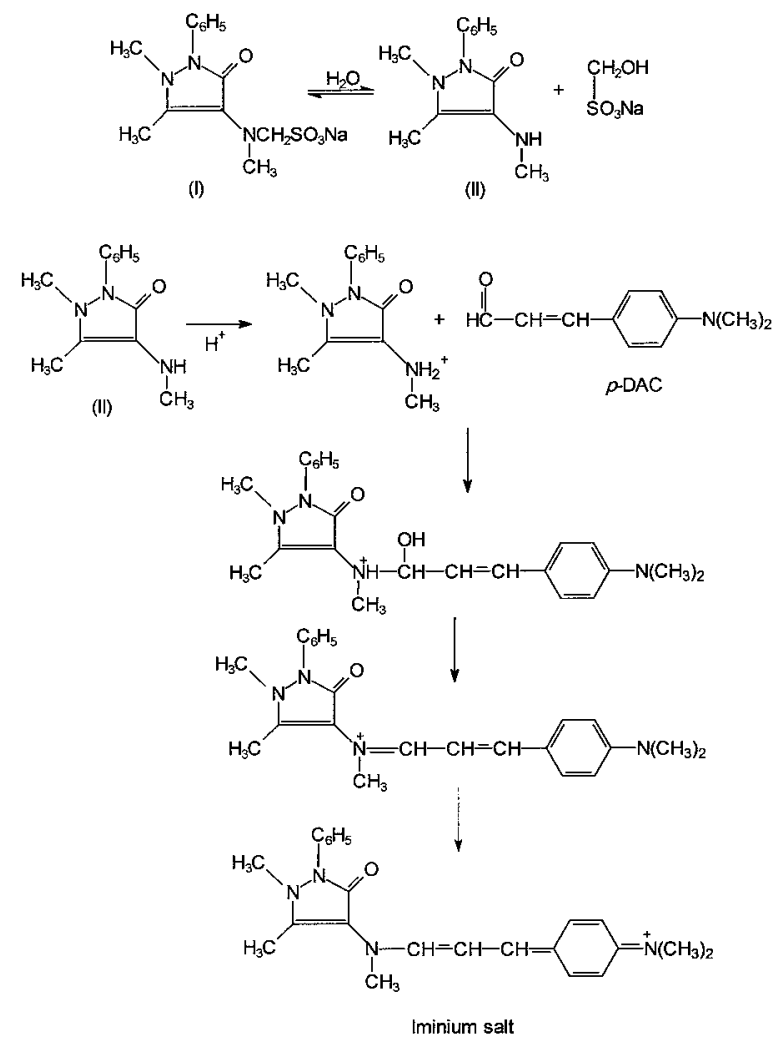

Scheme 1

After that, the carrier stream merged with a reagent stream of $p$ DAC $0.054 \%(\mathrm{~m} / \mathrm{v})$ prepared in $\mathrm{HCl} 2.22 \times 10^{-2} \mathrm{~mol} \mathrm{~L} \mathrm{~L}^{-1}$ pumped by a peristaltic pump (PP) at $1.70 \mathrm{~mL} \mathrm{~min}^{-1}$. The mixture passed through the reaction coil $(\mathrm{RC}, 250 \mathrm{~cm})$ at room temperature and the red-orange product that formed was carried to the flow injection spectrophotometric cell. The absorbance of the colored product was measured at $510 \mathrm{~nm}$ in the detector previously adjusted to zero with the carrier SDS solution converging with the reagent stream in the absence of novalgin. The absorbance was recorded continuously on a computer.

A series of novalgin standard solutions was injected into the reagent stream via an injection valve. The product formed was continuously monitored. A standard calibration graph was prepared by plotting peak height versus novalgin concentration over the range of $1.45 \times 10^{-6}$ to $2.90 \times 10^{-5} \mathrm{~mol} \mathrm{~L}^{-1}$ (equivalent to $0.5-10.0 \mu \mathrm{g} \mathrm{mL}^{-1}$ ).

\section{Sample preparation and analytical applications}

Samples of pharmaceutical formulations (A-G) containing novalgin in several dosage forms, both solid and liquid, were purchased in local drugstores in Araraquara city (Brazil) and analyzed by the proposed method.

Tablets. Twenty tablets of each commercial brand pharmaceutical to be studied were weighed exactly and grounded to a fine powder. A portion of this powder equivalent to approximately $2.5 \mathrm{mg}$ of novalgin was accurately weighed. The sample was shaken with $10 \mathrm{~mL}$ of deionized water in a magnetic stirrer for $5 \mathrm{~min}$ and diluted with deionized water in a $25 \mathrm{~mL}$ volumetric flask. In the sequence, this solution was filtered through Whatman 42 filter paper and an aliquot of 1.25 $\mathrm{mL}$ of filtrate was transferred to a $25 \mathrm{~mL}$ volumetric flask and 5 $\mathrm{mL}$ of SDS $0.10 \mathrm{~mol} \mathrm{~L}^{-1}$ was added and the volume was completed with water. This solution was analyzed according to 


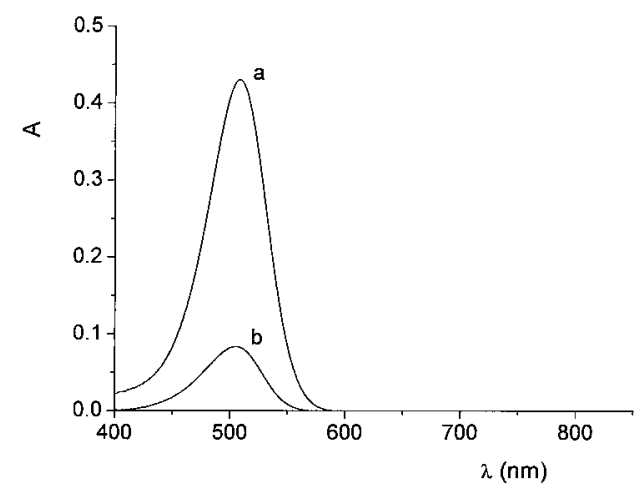

Fig. 2 Absorption spectra of the reaction product: (a) in the presence of SDS and (b) in the absence of SDS. Conditions of the reaction carried out in $5 \mathrm{~mL}$ volumetric flask: $1.50 \mathrm{~mL}$ of the $p$-DAC $0.17 \%(\mathrm{~m} / \mathrm{v})$ prepared in $\mathrm{HCl} 4.79 \times 10^{-2} \mathrm{~mol} \mathrm{~L}^{-1} ; 250 \mu \mathrm{L}$ of novalgin stock solution $2.90 \times 10^{-4} \mathrm{~mol} \mathrm{~L}^{-1}$ and $850 \mu \mathrm{L}$ of SDS solution 0.10 $\mathrm{mol} \mathrm{L}{ }^{-1}$. Measurements taken at $25^{\circ} \mathrm{C}$.

the recommended procedure.

Solutions. Convenient aliquots containing about $125.0 \mathrm{mg}$ of novalgin were transferred into a $250 \mathrm{~mL}$ volumetric flask and diluted to the mark with deionized water. Then, $250 \mu \mathrm{L}$ of this solution was transferred to a $25 \mathrm{~mL}$ volumetric flask and $5 \mathrm{~mL}$ of SDS $0.10 \mathrm{~mol} \mathrm{~L}^{-1}$ was added and the volume was completed with water. This solution was analyzed according to the recommended procedure.

\section{Reference method}

For accuracy assessment of the results obtained by the proposed method, novalgin pharmaceutical formulations were analyzed using the iodometric reference method. ${ }^{5}$

\section{Results and Discussion}

Novalgin ((I), Scheme 1) is an aromatic tertiary amine; in aqueous solutions, it readily undergoes hydrolysis, ${ }^{30}$ forming the 4-methylaminoantipyrine ((II), Scheme 1), ${ }^{31}$ a secondary aromatic amine, which can react with $p$-DAC. The reaction between secondary aromatic amines and $p$-DAC is assumed to take place via the condensation of the protonated secondary amino group with the carbonyl group of the reagent to produce an imminium salt. ${ }^{32-34}$ The probable mechanism for this reaction is shown in Scheme 1, which is to a large extent based on reactions suggested in the literature. ${ }^{32-34}$

It is known that micellar media are capable of changing the equilibrium, kinetic and spectral properties of reactions in which they are involved, and this has been used to improve the characteristics of analytical procedures. ${ }^{27}$ The effect of surfactant micelles in the condensation of aldehydes, such as $p$ DAC, with amines has been subject of a number of publications. ${ }^{35-37}$ However, there are no reports on the use of the micelles in the condensation of novalgin with $p$-DAC.

Preliminary experiments revealed that, in the presence of SDS, a significant enhancement of more than five orders of magnitude in the sensitivity of the reaction was observed and no shift in the absorption maximum takes place (Fig. 2).

On the basis of these results, a new flow injection procedure with spectrophotometric detection was developed based on the condensation reaction of novalgin with $p$-DAC in micellar medium and diluted acid solution.
Table 1 Optimization of experimental variables considered for a $2^{3}$ factorial design to the FI parameters

\begin{tabular}{lcc}
\hline \multirow{2}{*}{ FI variable } & \multicolumn{2}{c}{ Coded level } \\
\cline { 2 - 3 } & -1 & +1 \\
\hline Total flow rate/mL $\mathrm{min}^{-1}$ & 5.00 & 6.25 \\
Sample loop/ $\mu \mathrm{L}$ & 125 & 375 \\
Reaction coil/cm & 50 & 100 \\
\hline
\end{tabular}

\section{Optimization}

For the optimization of the flow injection method, the FI parameters and the chemical variables were investigated separately. The optimization was developed by experimental design, including two kinds of designs: the factorial design to evaluate which of the variables were significant factors and the central composite design, to obtain the response surface from which the optimal factors that give a maximum response can be deduced.

\section{Optimization of FI parameters}

Preliminary experiments under continuous flow conditions were carried out to test the manifold configuration and the approximate ranges of the tested parameters. The design of the manifold selected is shown in Fig. 1. The best results were obtained when the sample was injected into a stream of SDS carrier and then combined by merging the carrier with the stream of mixed $p$-DAC/ $\mathrm{HCl}$ reagent. In this experiment, the carrier stream of SDS was pumped at a flow rate higher than that of the reagent stream of $p$-DAC/ $\mathrm{HCl}$. Adopting this strategy, a stable baseline and an effective mixing of the sample and reagent solutions were achieved, affording an acceptable peak shape and sampling rate. In addition to the improvement in the analytical performance, this strategy enabled the reduction of the reagent consumed per determination.

The factors affecting the FI procedure were examined initially by a $2^{3}$ factorial design. The variables together with the levels examined are given in Table 1. For this design, eight experiments were necessary, which were realized in triplicate and randomized to eliminate environmental variation. In this study, the concentrations of reagents were kept constant: $p$ DAC $0.040 \%(\mathrm{~m} / \mathrm{v})$ prepared in $\mathrm{HCl} 1.20 \times 10^{-2} \mathrm{~mol} \mathrm{~L}^{-1}$, SDS $0.02 \mathrm{~mol} \mathrm{~L}^{-1}$ and novalgin solution $2.90 \times 10^{-5} \mathrm{~mol} \mathrm{~L}^{-1}$. The response selected was the absorbance intensity.

The influence of the sample volume on the transient peak was studied by changing the length of the sampling loop. Based on the previous experiments in the FI system with respect to the flow rate of the carrier and reagent solutions, we knew that the best results could be obtained when the flow rate of SDS carrier was higher than that of the $p$-DAC/ $\mathrm{HCl}$ reagent. So, Tygon ${ }^{\circledR}$ tubes of the 2.06 and $1.42 \mathrm{~mm}$ i.d. were used to propel SDS and $p$-DAC/ $\mathrm{HCl}$ solutions, respectively. The optimal total flow rate (carrier plus reagent streams) was determined by varying the rotation speed of the peristaltic pump producing the total flow rate, as shown in Table 1.

The effects of the individual factors and their combinations were determined using the Statistic program. The results are represented in a Pareto chart (Fig. 3), which is a horizontal barchart. The length of each bar on the chart is proportional to the absolute value of its associated estimated effect or the standardized effect. The chart includes a vertical line that corresponds to the $95 \%$ limit indicating statistical significance. An effect is therefore significant if its corresponding bar crosses 


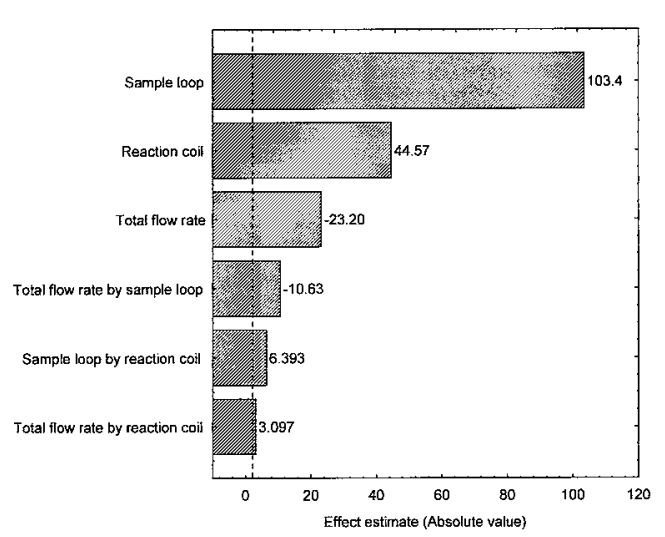

Fig. 3 Standardized effects of sample loop, total flow rate, reaction coil and their interaction effects on the absorbance measurements ( $\lambda$ $=510 \mathrm{~nm}$ ).

Table 2 Central composite design to the FI variables

\begin{tabular}{cccccc}
\hline \multirow{2}{*}{ FI variable } & \multicolumn{5}{c}{ Coded level } \\
\cline { 2 - 6 } & -1.41 & -1.0 & 0 & 1.0 & 1.41 \\
\hline Sample loop $/ \mu \mathrm{L}$ & 754.0 & 792.0 & 880.0 & 968.0 & 1005.0 \\
Reaction coil/cm & 200.0 & 214.5 & 250.0 & 285.5 & 300.0 \\
\hline
\end{tabular}

this vertical line. The most important effects correspond to the sample loop and the reaction coil (Fig. 3). Hence, these effects were studied more carefully.

Since the total flow rate did not have an important effect, a

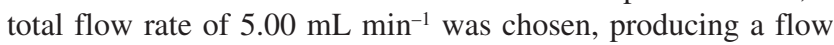
with acceptable peak shapes, sensitivity, reagent consumption and reaction time.

The central composite design was implemented to investigate the effect of the sample loop and the reaction coil on the absorbance signal, aiming at the highest sensitivity, in which the two variables were codified in five levels including four central points. For this design proposal, the variables considered and the levels examined are given in Table 2.

Figure 4 shows the response surface estimated as a function of the sample loop and the reaction coil. A statistically significant quadratic model accounting for $99.2 \%$ of the variance was fitted to the data at a $95.0 \%$ confidence level. Analyzing the fitted surface, it is possible to identify the points referring to the best conditions, which were a sample loop of the $880 \mu \mathrm{L}$ and a reaction coil of $250 \mathrm{~cm}$.

\section{Optimization of chemical variables}

The factors affecting the sensitivity of colored product resulting from the reaction of the novalgin with $p$-DAC, in the presence of SDS in acid medium, were carefully studied. This study was conducted using the already optimized conditions (sample loop, reaction coil and total flow rate). For this purpose, a $2^{3}$ factorial design was utilized. The factors and their examined levels are given in Table 3 . For each factor, an upper $(+1)$ and a lower $(-1)$ level were selected based on preliminary experiments carried out in our laboratory. For this design, eight experiments were necessary, which were carried out in triplicate and randomized to eliminate the environmental variations. The final concentration of novalgin was kept constant at $2.90 \times 10^{-5}$ $\mathrm{mol} \mathrm{L} \mathrm{L}^{-1}$ in all experiments.

The individual effects of the various parameters as well as

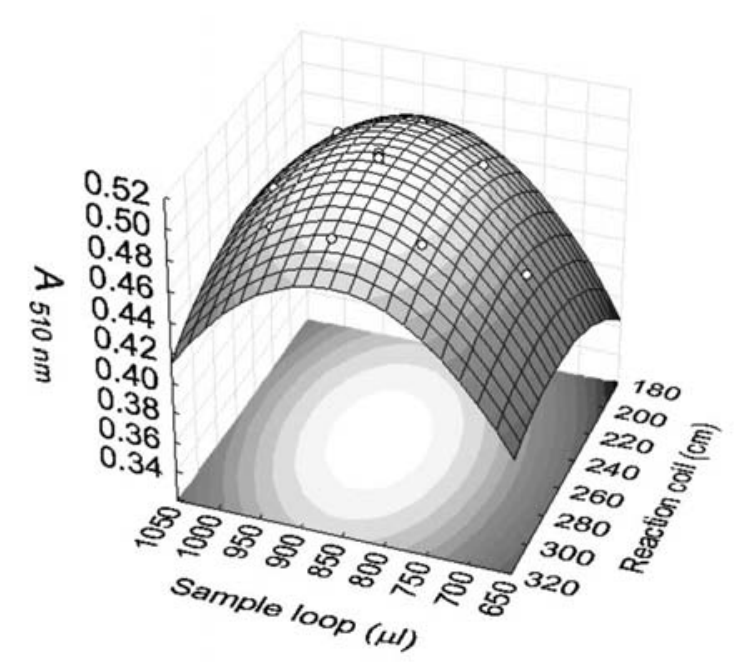

Fig. 4 Three-dimensional plot of the optimized surface response of FI measurements at variable sample loop and reaction coil sizes.

Table 3 Optimization of experimental variables considered for a $2^{3}$ factorial design to the chemical variables

\begin{tabular}{lcc}
\hline \multirow{2}{*}{ Chemical variable } & \multicolumn{2}{c}{ Coded level } \\
\cline { 2 - 3 } & -1 & +1 \\
\hline$[\mathrm{SDS}]_{\text {final }} / \mathrm{mol} \mathrm{L}^{-1}$ & $1.00 \times 10^{-2}$ & $2.00 \times 10^{-2}$ \\
{$[p-\mathrm{DAC}]_{\text {final }}, \%(\mathrm{~m} / \mathrm{v})$} & 0.045 & 0.050 \\
{$[\mathrm{HCl}]_{\text {final }} / \mathrm{mol} \mathrm{L}^{-1}$} & $1.90 \times 10^{-2}$ & $2.04 \times 10^{-2}$ \\
\hline
\end{tabular}

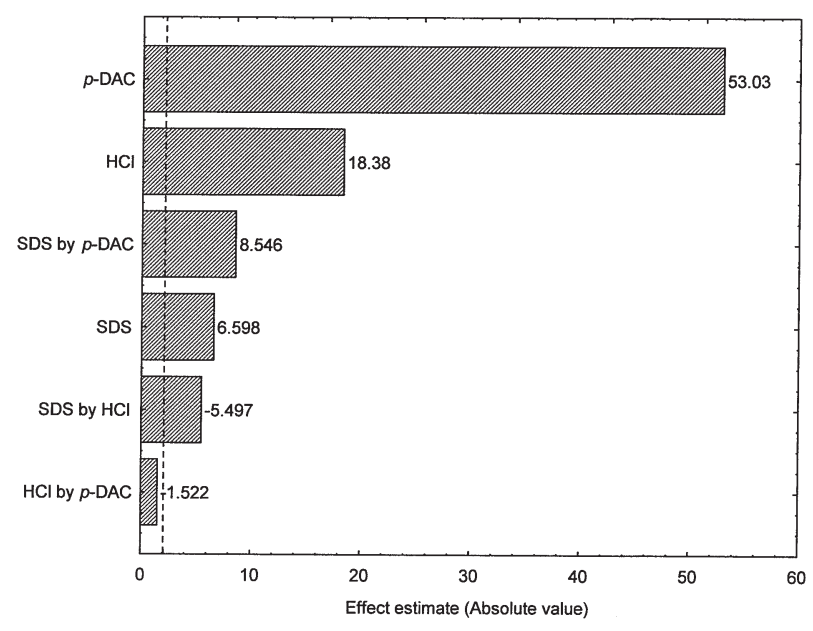

Fig. 5 Standardized effects of $p$-DAC, $\mathrm{HCl}$ and SDS concentrations and their interaction effects on the absorbance measurements $(\lambda=510 \mathrm{~nm})$.

their interactions can be discussed from the Pareto chart illustrated in Fig. 5.

From Fig. 5, it is obvious that the p-DAC concentration was the most significant factor, with a positive impact, indicating that the best results can be obtained when this factor is adjusted to a high level $(+1)$. The individual effect of the $\mathrm{HCl}$ concentration also was significant with a positive impact. The individual effect of the SDS concentration and the interaction effects between all factors also were significant, but less 
Table 4 Central composite design to the chemical variables

\begin{tabular}{lccccc}
\hline & \multicolumn{5}{c}{ Coded level } \\
\cline { 2 - 5 } Chemical variable & -1.41 & -1.0 & 0 & 1.0 & 1.41 \\
\hline$[\mathrm{HCl}]_{\text {final }} / \mathrm{mol} \mathrm{L}_{\text {-1 }}$ & $2.04 \times 10^{-2}$ & $2.09 \times 10^{-2}$ & $2.22 \times 10^{-2}$ & $2.35 \times 10^{-2}$ & $2.40 \times 10^{-2}$ \\
{$[p \text {-DAC }]_{\text {final }}, \%(\mathrm{~m} / \mathrm{v})$} & 0.050 & 0.051 & 0.053 & 0.055 & 0.056 \\
\hline
\end{tabular}

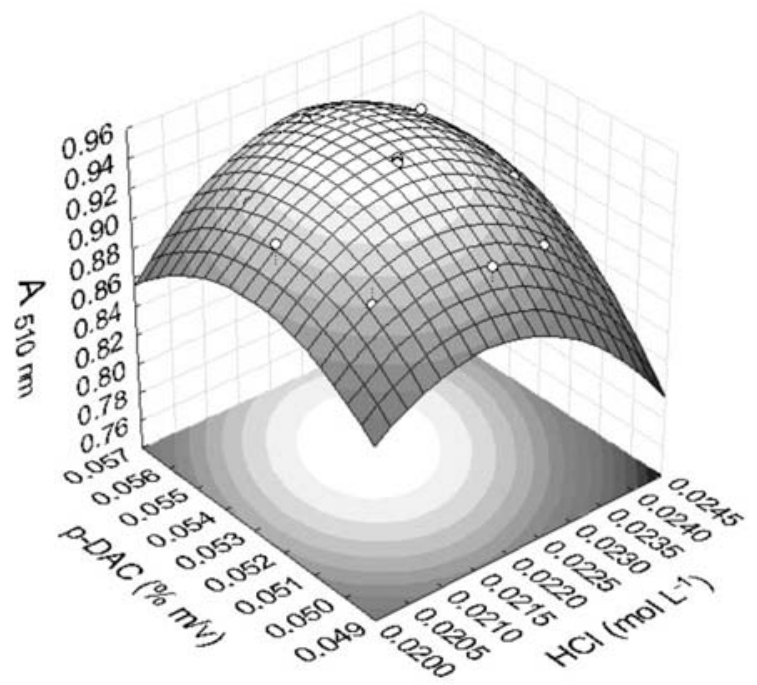

Fig. 6 Three-dimensional plot of the optimized surface response of absorbance measurements at variable $p$-DAC and $\mathrm{HCl}$ concentrations.

important. So, the SDS concentration was set at $2.00 \times 10^{-2} \mathrm{~mol}$ $\mathrm{L}^{-1}$ (the highest concentration level studied). In the sequence, a new central composite design was evaluated to investigate the effect of $p$-DAC and $\mathrm{HCl}$ concentrations on the absorbance signal, in which the two variables were codified in five levels including four central points. For this design, the variables considered and their examined levels are given in Table 4.

Figure 6 shows the response surface estimated as a function of $\mathrm{HCl}$ and $p$-DAC concentrations. A statistically significant quadratic model accounting for $89.0 \%$ of the variance was fitted to the data at a $95 \%$ confidence level. Analyzing the fitted surface, it is possible to identify that the points referring to the best conditions were: $p$-DAC $0.054 \%(\mathrm{~m} / \mathrm{v})$ prepared in $\mathrm{HCl}$ $2.22 \times 10^{-2} \mathrm{~mol} \mathrm{~L}^{-1}$, which showed the highest absorbance values.

\section{Analytical data}

The developed analytical method was validated by evaluating the linear dynamic range, precision, limit of detection (LOD) and limit of quantification (LOQ) as well as by applying the standard addition technique.

Under the optimized experimental conditions (shown in Fig. 1), the linear calibration curve was constructed from $1.45 \times 10^{-6}$ to $2.90 \times 10^{-5} \mathrm{~mol} \mathrm{~L}^{-1}$ (equivalent to $0.5-10.0 \mu \mathrm{g} \mathrm{mL}^{-1}$ ) of the novalgin standard solutions. The least square treatment of calibration data $(n=8)$ yielded the regression equation: $A=$ $0.0019( \pm 0.0013)+2.7535 \times 10^{4}( \pm 81.142) C$, where $A$ is the absorbance of the peak at $510 \mathrm{~nm}$ and $C$ novalgin concentration in $\mathrm{mol} \mathrm{L}^{-1}$. The correlation coefficient was 0.9999 , indicating the excellent linearity of the calibration curve.

Assay precision was defined by determining intraday and
Table 5 Recovery data for novalgin spiked in pharmaceutical formulations

\begin{tabular}{cccc}
\hline Sample & Added $/ \mu \mathrm{g} \mathrm{mL}^{-1}$ & Found $/ \mu \mathrm{g} \mathrm{mL}^{-1}$ & Recovery, \% \\
\hline $\mathrm{A}^{\mathrm{a}}$ & - & 2.00 & - \\
& 1.00 & 2.97 & 97.3 \\
& 2.00 & 4.05 & 102.5 \\
& 3.00 & 5.00 & 100.0 \\
& 4.00 & 6.02 & 100.5 \\
$\mathrm{~B}^{\mathrm{a}}$ & & & $\mu^{\mathrm{c}}=100.1 \pm 2.1$ \\
& 1.00 & 1.99 & - \\
& 2.00 & 4.97 & 98.0 \\
& 3.00 & 4.98 & 100.8 \\
& 4.00 & 6.06 & 99.5 \\
$\mathrm{C}^{\mathrm{b}}$ & & & 101.8 \\
& 1.00 & 1.98 & $\mu^{\mathrm{c}}=100.0 \pm 1.6$ \\
& 2.00 & 3.01 & - \\
& 3.00 & 4.00 & 103.0 \\
& 4.00 & 5.02 & 100.8 \\
& & 5.95 & 99.3 \\
$\mathrm{D}^{\mathrm{b}}$ & - & & $\mu^{\mathrm{c}}=101.1 \pm 1.5$ \\
& 1.00 & 3.01 & 99.0 \\
& 2.00 & 3.00 & 100.0 \\
& 3.00 & 5.01 & 99.7 \\
& 4.00 & 5.00 & $\mu^{\mathrm{c}}=99.6 \pm 0.4$ \\
\hline & & 6.00 & \\
\hline
\end{tabular}

a. Solutions.

b. Tablets.

c. Average \pm standard deviation (SD) of four determinations.

interday variation, expressed as relative standard deviation (RSD). The interday variation was evaluated over 3 days. The intraday precision and interday precision were studied from 10 replicate analyses of $1.45 \times 10^{-5} \mathrm{~mol} \mathrm{~L}^{-1}$ novalgin solution. The coefficients of variation were 0.7 and $1.2 \%$, respectively. The smallest novalgin concentration on the calibration curve was analyzed by the proposed method $(n=20)$ and the standard deviations of the measurements were calculated and used to estimate the LOD and LOQ according to IUPAC recomendations. ${ }^{38}$ The LOD and LOQ were $1.31 \times 10^{-7}$ and $4.40 \times 10^{-7} \mathrm{~mol} \mathrm{~L}^{-1}$, respectively with an RSD of $2.0 \%$.

Repeatability of the proposed method was measured for a series of ten independent determinations at two concentration levels of a sample solution. The relative standard deviations were found to be 0.7 and $0.2 \%$ for the determination of $5.80 \times$ $10^{-6}$ and $1.45 \times 10^{-5} \mathrm{~mol} \mathrm{~L}^{-1}$ of novalgin, respectively.

In order to investigate the presence of matrix effects on the proposed method, a recovery study was carried out. In this study, $1.00,2.00,3.00$ and $4.00 \mu \mathrm{g} \mathrm{mL}^{-1}$ of novalgin reference solutions were added in four selected pre-analyzed pharmaceutical preparations. The results presented in Table 5 reveal the absence of significant matrix effects on the proposed FI procedure. 
Table 6 Determination of novalgin in commercial pharmaceutical formulations

\begin{tabular}{|c|c|c|c|c|c|c|}
\hline \multirow{2}{*}{\multicolumn{2}{|c|}{ Sample }} & \multirow{3}{*}{$\begin{array}{c}\begin{array}{c}\text { Label } \\
\text { to content }\end{array} \\
320\end{array}$} & \multicolumn{3}{|c|}{ Proposed method } & \multirow{3}{*}{$\begin{array}{c}\text { Reference method }^{5} \\
\text { Found }^{\mathrm{c}} \\
320 \pm 2\end{array}$} \\
\hline & & & \multirow{2}{*}{$\begin{array}{l}\text { Found }^{\mathrm{c}} \\
320 \pm 2\end{array}$} & \multirow{2}{*}{$\begin{array}{c}t \text { value }(2.78)^{\mathrm{d}} \\
0.17\end{array}$} & \multirow{2}{*}{$\frac{F \text { value }(19.00)^{\mathrm{d}}}{1.00}$} & \\
\hline Tablet $^{\mathrm{a}}$ & A & & & & & \\
\hline & B & 250 & $245 \pm 2$ & 1.98 & 2.25 & $245 \pm 3$ \\
\hline & $\mathrm{C}$ & 500 & $494 \pm 1$ & 0.19 & 4.00 & $494 \pm 2$ \\
\hline & D & 500 & $500 \pm 4$ & 0.30 & 1.00 & $501 \pm 4$ \\
\hline & E & 500 & $516 \pm 3$ & 0.59 & 4.00 & $518 \pm 3$ \\
\hline & $\mathrm{F}$ & 500 & $497 \pm 3$ & 0.28 & 1.00 & $497 \pm 3$ \\
\hline Solution ${ }^{\mathrm{b}}$ & G & 333 & $337 \pm 4.9$ & 0.07 & 6.25 & $337 \pm 1.9$ \\
\hline & $\mathrm{H}$ & 500 & $502 \pm 1.7$ & 1.39 & 5.44 & $499 \pm 2.8$ \\
\hline
\end{tabular}

a. Label to content for tablets: $\mathrm{mg}$ tablet ${ }^{-1}$. b. Label to content for solutions: $\mathrm{mg} \mathrm{mL}^{-1}$. c. Average \pm standard deviation (SD) of three independent analyses. d. Theoretical values of $t$ and $F$ at $95 \%$ confidence level.

Table 7 Comparison of the analytical performance of the previously reported FI methods and the proposed in this work for the determination of novalgin

\begin{tabular}{lcccc}
\hline \multicolumn{1}{c}{ Detection } & Linear range/mol L & Detection limit/mol L-1 & Sample through/sample $\mathrm{h}^{-1}$ & Ref. \\
\hline Amperometric & $2.90 \times 10^{-5}-1.45 \times 10^{-4}$ & $2.61 \times 10^{-7}$ & 71 & 20 \\
Turbidimetric & $5.00 \times 10^{-4}-2.50 \times 10^{-3}$ & $1.30 \times 10^{-4}$ & 45 & 21 \\
Potentiometric & $8.00 \times 10^{-4}-1.00 \times 10^{-1}$ & $9.00 \times 10^{-4}$ & 108 & 22 \\
Chemiluminescence & $1.16 \times 10^{-6}-2.90 \times 10^{-5}$ & $4.35 \times 10^{-7}$ & 60 & 23 \\
Fluorometric & $1.60 \times 10^{-6}-1.20 \times 10^{-5}$ & - & 40 & 24 \\
Spectrophotometric & $1.40 \times 10^{-4}-7.00 \times 10^{-4}$ & $6.00 \times 10^{-5}$ & 60 & 25 \\
Spectrophotometric & $2.90 \times 10^{-5}-1.16 \times 10^{-3}$ & $2.90 \times 10^{-6}$ & 50 & 26 \\
Spectrophotometric & $1.45 \times 10^{-6}-2.90 \times 10^{-5}$ & $1.31 \times 10^{-7}$ & 72 & Proposed method \\
\hline
\end{tabular}

\section{Study of interferences}

The effects of the common excipients and of the associated drugs commonly present in commercial pharmaceutical formulations involving novalgin were carefully examined. The concomitants studied were lactose, sucrose, citric acid, starch, sodium saccharin, sodium sulfite, sodium benzoate, talc, magnesium stearate, polyvinylpirrolidone, sorbitol, methyl cellulose, caffeine, aspirin, acetaminophen, ascorbic acid, phenacetin, oxyphenbutazone, acid promethazine hydrochloride, adiphenine hydrochloride, butylscopolamine bromide, salycilamide and phenobarbital. For this study, solutions containing novalgin and one of the concomitants taken separately in concentrations equal or 10 times greater than that of novalgin were shaken with deionized water in a magnetic stirrer for $5 \mathrm{~min}$, diluted and filtered where it was necessary. These were analyzed under the same conditions as those described in the recommended procedure.

The effect of each excipient was considered to be an interference when the signal showed an error greater than or equal to $3.0 \%$ in the determination of the drug. No interferences were observed in the presence of the substances tested.

\section{Analytical application}

The applicability of the proposed method for the determination of novalgin in commercial dosage forms was examined by analyzing marketed products. The results were statistically ${ }^{39}$ compared with those obtained by the iodometric reference method $^{5}$ and are summarized in Table 6 . It is evident that the calculated $t$ and $F$ values are less than the theoretical ones at $95 \%$ confidence level, indicating that there is no significant difference between either methods concerning precision and accuracy in the determination of novalgin in pharmaceutical formulations. The flow system selected provides a sampling frequency of 72 samples $\mathrm{h}^{-1}$.

Compared with previously reported methods for the determination of novalgin the proposed method was more sensitive (lower detection limit) than other FI methods reported in literature (Table 7).

\section{Conclusions}

The sensitivity of the reaction between novalgin and $p$-DAC in dilute acid medium was increased approximately 5.6-fold in micellar SDS medium and this effect was exploited to develop a very sensitive spectrophotometric FI procedure $(\mathrm{LOD}=1.31 \times$ $10^{-7} \mathrm{~mol} \mathrm{~L}^{-1}$ ) for novalgin quantification.

The proposed FI spectrophotometric method has the advantages of simplicity, high sampling rate $\left(72\right.$ samples $\left.\mathrm{h}^{-1}\right)$, high sensitivity, and repeatability; it generates low levels of waste and does not involve specific or complex pretreatment of the samples.

Its usefulness for novalgin determination in commercial liquid and solid dosage forms was demonstrated, suggesting its use as a reliable and advantageous alternative to most other previously reported methods.

\section{Acknowledgements}

We would like to thank FAPESP and CNPq Foundations (Brazil) for financial support. 


\section{References}

1. "Martindale the Extra Pharmacopoeia: Evaluated Information on the World's Drugs and Medicines", ed. J. E. F. Reynolds, 31st ed., 1996, The Royal Pharmaceutical Society, London, 39.

2. H. Ergun, D. A. C. Frattarelli, and J. V. Aranda, J. Pharm. Biomed. Anal., 2004, 35, 479.

3. J. S. Albuquerque, V. L. Silva, F. Lima, A. N. Araújo, and M. C. B. S. M. Montenegro, Anal. Sci., 2003, 19, 691.

4. M. K. Srivastava, S. Ahmad, D. Singh, and I. S. Shukla, Analyst, 1985, 110, 735.

5. European Pharmacopoeia, Council of Europe, 2005, v.2, France, 2002.

6. M. C. Inandar and N. M. Sanghavi, Indian J. Pharm., 1971, 33, 94.

7. N. H. Eddine, F. Bressolle, B. Mandrou, and H. Fabre, Analyst, 1982, 107, 67.

8. G. B. Golubitskii, E. V. Budko, and V. M. Ivanov, J. Anal. Chem., 2006, 61, 67.

9. I. Baranowska, P. Markowski, and J. Baranowski, Anal. Chim. Acta, 2006, 570, 46.

10. M. F. S. Teixeira, L. H. Marcolino, O. Fatibello-Filho, E. R. Dockal, and E. T. G. Cavalheiro, J. Braz. Chem. Soc., 2004, 15, 803.

11. F. Belal, Electroanalysis, 1992, 4, 589.

12. O. A. Zaprorozhtes, E. A. Krushinskaya, N. A. Lipkovskaya, and V. V. Sukhan, J. Anal. Chem., 2001, 56, 524.

13. N. Erk and F. Onur, Anal. Lett., 1997, 30, 1201.

14. N. Acar and F. Onur, Anal. Lett., 1996, 29, 763.

15. K. A. Sakiara, L. Pezza, C. B. Melios, H. R. Pezza, and M. De Moraes, Farmaco, 1999, 54, 629.

16. S. Z. Qureshi, A. Saeed, and S. Haque, Michrochem. J., 1990, $41,362$.

17. S. Z. Qureshi, A. Saeed, and J. Hassan, Talanta, 1989, 36, 869.

18. B. Moreli, J. Pharm. Biomed. Anal., 2003, 33, 423.

19. M. S. Garcia, M. J. Albero, C. Sanchez-Pedreno, and M. S. Abuherba, Eur. J. Pharm. Biopharm., 2005, 61, 87.

20. E. P. Medeiros, S. Castro, F. M. Formiga, S. R. B. Santos,
M. C. U. Araújo, and V. B. Nascimento, Michrochem. J., 2004, 78, 91 .

21. L. H. Marcolino-Jr., V. G. Bonifácio, O. Fatibello-Filho, and M. F. S. Teixeira, Quim. Nova, 2005, 28, 783.

22. J. S. Albuquerque, V. L. Silva, F. Lima, A. N. Araújo, and M. C. B. S. M. Montenegro, Anal. Sci., 2003, 19, 691.

23. Y. M. Huang, C. Zhang, X. R. Zhang, and Z. J. Zhang, Fresenius J. Anal. Chem., 1999, 365, 381.

24. T. Perez-Ruiz, C. Martinez-Lozano, V. Tomás, and J. Carpena, Microchem. J., 1993, 47, 296.

25. A. V. Pereira, L. Penckowski, M. Vosgerau, M. F. Sassá, and O. Fatibello-Filho, Quim. Nova, 2002, 25, 553.

26. J. L. F. C. Lima, S. M. O. Sá, J. L. M. Santos, and E. A. G. Zagatto, J. Pharm. Biomed. Anal., 2003, 32, 1011.

27. J. S. Esteve-Romero, E. F. Simó-Alfonso, M. C. GarciaAlvarez-Coque, and G. Ramis-Ramos, Trends Anal. Chem., 1995, 14, 29.

28. C. A. Georgiou, M. A. Koupparis, and T. P. Hadjiioannou, Talanta, 1991, 38, 689.

29. F. R. P. Rocha, J. A. Nobrega, and O. Fatibello-Filho, Green Chemistry, 2001, 3, 216.

30. H. Fabre, N. H. Eddine, F. Bressolle, and B. Mondrou, Analyst, 1982, 107, 61.

31. S. Ono, R. Onishi, and K. Kawahara, Yakugaku Zasshi, 1966, 86, 11.

32. N. H. Zawilla, A. A. Mohammad, N. M. El Kousy, and S. M. El-Moghazy Aly, J. Pharm. Biomed. Anal., 2002, 27, 243.

33. A. A. El-Sherif, M. I. Walash, M. F. El-Tarras, and A. O. Osman, Anal. Lett., 1997, 30, 1881.

34. M. A. Gotardo, A. C. Gigante, L. Pezza, H. R. Pezza, Talanta, 2004, 64, 361.

35. S. Y. Doronin, R. K. Chernova, and N. N. Gusakova, Russ. J. Gen. Chem., 2005, 75, 261.

36. A. K. Yatziirsky, N. T. Yatzimirsky, and S. Krinova, Anal. Chem., 1994, 66, 2232.

37. J. S. Esteve-Romero, L. M. Pons, M. C. Garcia-AlvarezCoque, and G. Ramis-Ramos, Anal. Lett., 1994, 27, 1557.

38. M. Thompson, S. L. R. Ellison, and R. Wood, Pure Appl. Chem., 2002, 74, 835.

39. J. C. Miller and J. N. Miller, "Statistics for Analytical Chemistry", 2nd ed., 1992, Ellis Horwood, London, 55. 